\title{
Efficacy and Tolerability of Tricyclic Antidepressants and SSRIs Compared With Placebo for Treatment of Depression in Primary Care: A Meta-Analysis
}

Bruce Arroll, $M B C b B, P b D^{1}$

Steve Macgillivray, $M A^{2}$

Simon Ogston, $\mathrm{PbD}, \mathrm{MA}, \mathrm{Ms}_{\mathrm{C}} \mathrm{C}^{2}$

Ian Reid, $M B, P b D, M R C P_{s y c h}{ }^{3}$

Frank Sullivan, PbD, FRCP, FRCGP 2

Brian Williams, $P b D^{4}$

Iain Crombie, PbD, Cstat, FFPHM ${ }^{2}$

${ }^{1}$ Department of General Practice and Primary Health Care, University of Auckland, NZ

${ }^{2}$ Department Community Health Services, University of Dundee, Dundee, UK

${ }^{3}$ Department of Psychiatry, University of Dundee, Dundee, UK

${ }^{4}$ Department of Social Work, University of Dundee, Dundee, UK

\begin{abstract}
PURPOSE Depression is common in primary care. There are no systematic reviews of depression treatment comparing antidepressants with placebo; hence, we do not know whether these medications are effective in primary care.
\end{abstract}

METHODS We searched the Cochrane Collaboration Depression, Anxiety and Neurosis Group register of controlled trials, MEDLINE, International Pharmaceutical abstracts, PsycINFO, and EMBASE. Abstracts of potential studies were reviewed independently by 2 authors. Studies needed to include randomized controlled trials of either a tricyclic antidepressant (TCA) or selective serotonin reuptake inhibitor (SSRI), or both, and placebo in a primary care setting. The data and quality of the studies were extracted and assessed by 2 authors blind to the other's choice. Disagreements were resolved by discussion. The main outcome measures were the standardized mean difference and weighted mean difference of the final mean depression scores, the relative risk of improvement, and the number withdrawing because of side effects. Pooling of results was done using Review Manager 4.2.2.

RESULTS There were 10 studies in which TCAs were compared with placebo, 3 in which SSRIs were compared with placebo, and 2 with both compared with placebo. One half of the studies were of low methodological quality, and nearly all studies were of short duration, typically 6 to 8 weeks. Pooled estimates of efficacy data showed a relative risk of $1.26(95 \% \mathrm{Cl}, 1.12-1.42)$ for improvement with TCAs compared with placebo; For SSRIs, relative risk was 1.37 (95\% Cl, 1.211.55). Most patients, $56 \%$ to $60 \%$, responded well to active treatment compared with $42 \%$ to $47 \%$ for placebo. The number needed to treat for TCAs was about 4 , and for SSRIs it was 6 . The numbers needed to harm (for withdrawal caused by side effects) ranged from 5 to 11 for TCAs and 21 to 94 for SSRIs. Low-dose (100 $\mathrm{mg}$ or $75 \mathrm{mg}$ ) as well as high-dose TCAs were effective.

CONCLUSION This systematic review is the first comparing antidepressants with placebo for treatment of depression in primary care. Both TCAs and SSRIs are effective. This review is also the first to show that low-dose TCAs are effective in primary care. Prescribing antidepressants in primary care is a more effective clinical activity than prescribing placebo.

Ann Fam Med 2005;3:449-456. DOI: 10.1370/afm.349.

\section{INTRODUCTION}

\section{CORRESPONDING AUTHOR}

Bruce Arroll, MBChB, PhD

Department of General Practice

and Primary Health Care,

University of Auckland, Private Bag 92019

Auckland, NZ

b.arroll@auckland.ac.nz
\}

$t$ is a paradox that whereas the great majority of patients with clinical depression are cared for by primary care physicians, most research findings upon which decisions are made have involved secondary care patients. This discrepancy is important because research suggests that patients with depressive disorders in primary care have different causes, abnormalities, and natural history than those of psychiatric inpatients or 
outpatients. ${ }^{1,2}$ Often depressed primary care patients report somatic symptoms, which include gastrointestinal, skeletal muscle, and cardiovascular complaints, as opposed to describing nonsomatic criteria for depression.

Doubts about the effectiveness of antidepressant medication and other therapies, such as cognitive therapy, may contribute to the variability in primary care management of depression. ${ }^{3,4}$ Up to $40 \%$ of depressed patients fail to show a response to first-line antidepressant drug treatment, ${ }^{5}$ and of those that do respond, only a proportion will achieve full recovery. ${ }^{6}$ One cohort study of primary care patients found that $60 \%$ of depressed patients treated with medication and 50\% with milder depression still met the criteria for caseness at 1 year. ${ }^{7}$

Recent reports have indicated an urgent need to review the evidence of only those studies of antidepressant efficacy on patient samples based in primary care. ${ }^{8,9}$ Several completed reviews and protocols are currently registered on the Cochrane database that consider the efficacy of antidepressants for the treatment of depression. None has specified a focus on patients treated in primary care. ${ }^{10}$ Systematic reviews of antidepressant medication often include patients seen in outpatient facilities rather than in primary care or at least recruited from primary care. ${ }^{11}$ Concern has been expressed about the relevance of secondary care studies to primary care patients. ${ }^{8,9}$ We are aware of only 2 published systematic reviews based on patients either seen or recruited in primary care. Both compared newer antidepressants with older antidepressants. The Mulrow et al review ${ }^{12}$ had a small section on antidepressant drugs vs placebo but reviewed only 4 studies. The MacGillivray et al review ${ }^{13}$ compared selective serotonin reuptake inhibitors (SSRIs) with tricyclic antidepressants (TCAs) and therefore comment only on relative efficacy. Comparison with placebo is needed to obtain absolute efficacy. These considerations indicate a persistent need to review the evidence of only those studies that have been conducted comparing antidepressant efficacy with placebo using patient samples based in primary care. ${ }^{8,9}$ The aim of this review was to review systematically the efficacy of antidepressant compared with placebo studies in treating depression in primary care.

\section{METHODS}

\section{Study Selection}

Studies were considered for this review if they were randomized, placebo-controlled trials using TCAs and/ or SSRIs and included primary care patients. Primary care patient samples were defined as an undifferentiated group of patients who are able to access medical care from a primary health care clinician. ${ }^{14}$ Participants had to be adults who had a diagnosis of depression (studies with predominately children or the elderly were excluded), because we wished to assess the dosage levels in adults, and lower doses of antidepressants are often used in the elderly. Studies could be in any language.

Our primary outcomes were the efficacy of TCAs and SSRIs in comparison with placebo. Secondary outcomes were the number reporting drug-related adverse events and the number withdrawing because of drugrelated adverse events. We also explored the effect of study quality on outcome, the effect of having primary care physicians as at least one half of the clinicians prescribing medications and assessing patients, and the effectiveness of low-dose of medication.

\section{Data Sources}

We electronically searched the Cochrane Collaboration Depression, Anxiety and Neurosis Group (CCDAN) register, MEDLINE, International Pharmaceutical abstracts, PsycINFO, and EMBASE up to February 2003 for any trials in which antidepressants were used in primary care. A follow-up search was done in September 2003, and a final search was done in December 2004. The search terms used were the names of all known antidepressant medications. There was no language restriction. Two reviewers independently assessed abstracts of all studies possible for inclusion for relevant study inclusion criteria. We searched for additional trials in the reference lists of initial studies identified and by scrutinizing other relevant review articles. We also contacted selected authors and experts.

\section{Data Extraction}

The methodological quality of the selected studies was assessed according to the recommendations of the Cochrane Collaboration Handbook. ${ }^{15}$ The components of quality were adequacy of sample size, allocation concealment, clear description of treatment, representative source of subjects, use of diagnostic criteria or clear specification of inclusion criteria, and either outcome measures described clearly or use of validated instruments. A score of 0 on any component caused the study to be rated as poor quality. Two reviewers independently extracted data using data extraction forms, and disagreements were resolved by discussion. A similar process was used for the validity assessment.

\section{Data Synthesis}

All data were analyzed using Review Manager (RevMan) 4.2.2, which is the Cochrane Collaboration software used for preparing systematic reviews. For continuous outcomes we calculated the standardized 


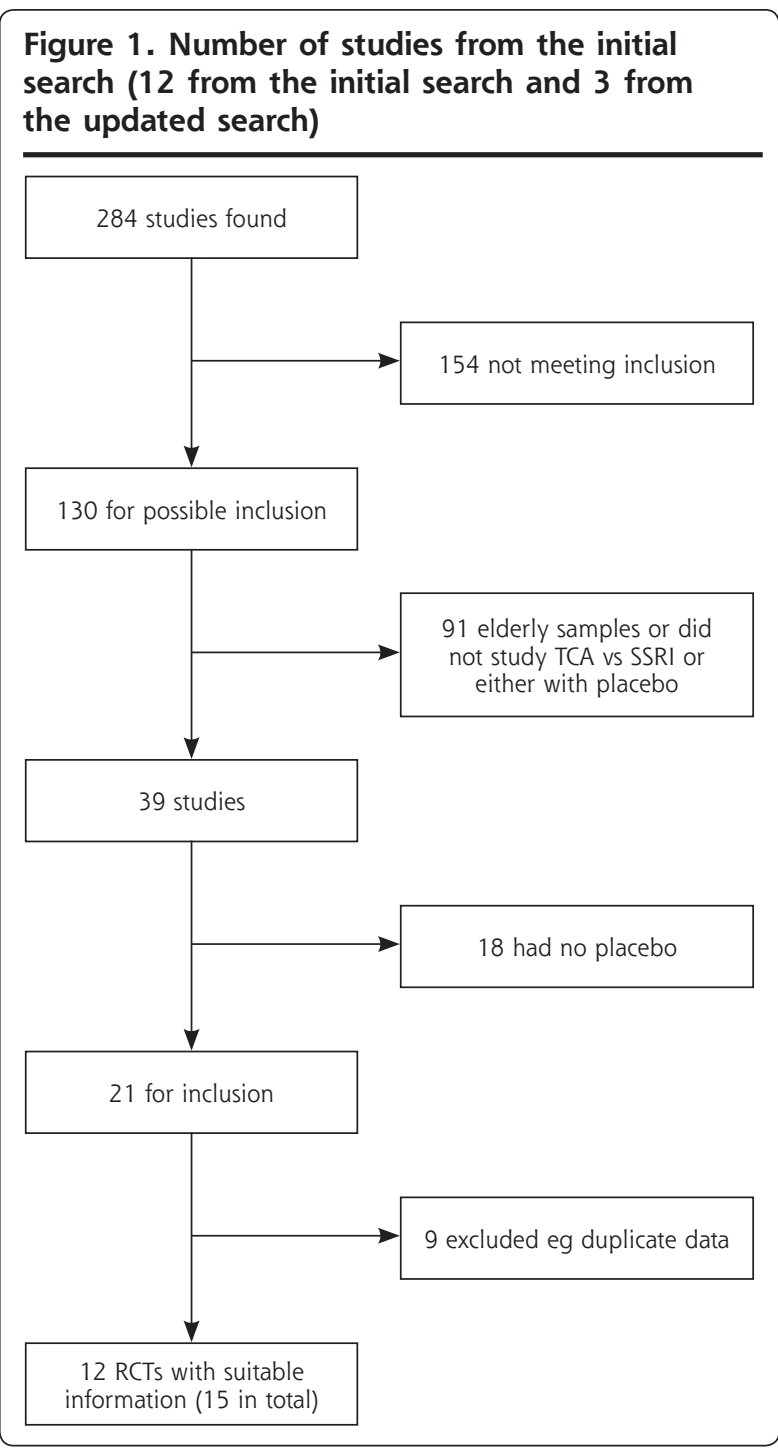

mean difference. Where the same outcome scale was used, we calculated the weighted mean difference. For dichotomous outcomes we calculated relative risk (RR) and the range of numbers needed to treat for statistically significant studies. We assessed heterogeneity using the Q statistic. ${ }^{15}$ Where data were available in graphic format only, an approximation of the mean was made to assess the outcomes. For data reported without standard deviations, the highest standard deviations in the outcome scores from the other studies were used. We also performed a funnel plot analysis to check for publication bias. There were a number of definitions for outcomes we described as "improvement": 4 definitions used $\leq 50 \%$ reduction in the Montgomery-Asberg Depression Rating Scale (MADRS), ${ }^{16-19} \leq 50 \%$ reduction in Hamilton Depression Rating Scale (HAMD), ${ }^{20} \leq 7$ on the HAMD scale, ${ }^{21}$ and $\leq 4$ points on $\mathrm{HAMD}^{22}$; and 3 definitions used global evaluation of improvement. ${ }^{23-25}$

\section{RESULTS}

Of the 284 articles identified from the initial search strategy, only 12 met the study criteria (Figure 1 ). Three additional studies were found in a search undertaken in September 2003. No further studies were found in December 2004. There were 890 participants in SSRI studies, 596 in TCA studies, and 1,267 patients on placebo (Table 1). ${ }^{16-30}$ Of the 5 possible SSRIs available, 2 studied sertraline, 3 studied escitalopram (a precursor of citalopram), and 1 studied citalopram. Of the TCAs available, 2 studied dothiepin, 4 studied amitriptyline, 2 studied mianserin, and 3 studied imipramine. Ten of the 15 studies were identified as having a competing interest.

Our results confirm that both TCA and SSRI are significantly effective compared with placebo (Figures 2 and 3). For depression scores the standardized mean difference for TCA vs placebo was -0.42 (95\% confidence interval $[\mathrm{CI}],-0.55$ to -0.3$)$. The relative risk for improvement using TCA medications was 1.26 (95\% CI, 1.12 to 1.42 ). For SSRI medications the relative risk for improvement was 1.37 (95\% CI, 1.21 to 1.55$)$. The number needed to treat for 1 improved patient ranged from 3 to 4 for the TCA studies that were statistically significant. Likewise, the number needed to treat was 6 for SSRIs. We performed an analysis with 5 studies (not shown) that had treatment group scores of $<8$ on the HAMD. The weighted mean difference was -3.68 (95\% $\mathrm{CI},-5.89$ to -1.47$)$. There was no significant heterogeneity for any analyses, so a fixed effects analysis was used. No significant differences were found for those studies in which means were approximated from graphs or standard errors were assumed from other studies compared with studies that had published data. A funnel plot of the TCA studies suggested that small studies with a small effect size might be missing (the funnel plot is not shown). The funnel plot methodology gives a qualitative view of publication bias but not a quantitative perspective and is therefore difficult to interpret.

The relative risk for adverse effects leading to study withdrawal for TCAs was 2.35 (95\% CI, 1.59 to 3.46)

(Figure 4) and for SSRIs the relative risk was 2.01 (95\% CI, 1.1 to 3.7 ) (Figure 5). The number needed to harm in terms of study withdrawal resulting from adverse effects for 2 statistically significant TCA studies was 5 and 10 . None of the 4 SSRI studies had statistically significant findings for adverse effects leading to withdrawal, but using the pooled figure and the range of baseline risks, the number needed to harm ranged from 21 to 94 .

Seven studies did not meet the minimum quality criteria on at least 1 of the key components of methodological quality. ${ }^{18,22,25,27-29} \mathrm{~A}$ score of 0 on any component caused the study to be rated as being poor quality. 


\begin{tabular}{|c|c|c|c|c|c|c|c|}
\hline Study & Quality* & Diagnosis & $\begin{array}{c}\text { TCA } \\
\text { Dose }^{\dagger}\end{array}$ & $\begin{array}{l}\text { Responsible } \\
\text { for Treatment }\end{array}$ & $\begin{array}{l}\text { Competing } \\
\text { Interest }\end{array}$ & $\begin{array}{l}\text { Study } \\
\text { Period }\end{array}$ & Outcome \\
\hline \multicolumn{8}{|l|}{ TCA vs placebo } \\
\hline Blashki et al26 & High & Heterogeneous & High and low & $\begin{array}{c}\text { GP and } \\
\text { psychiatrist }\end{array}$ & No & 4 wk & HAMD \\
\hline Brink et $\mathrm{al}^{27}$ & Low & Heterogeneous & High & GP & Yes & 6 wk & HAMD \\
\hline $\begin{array}{l}\text { Doogan } \varepsilon \\
\text { Langdon }{ }^{19 \ddagger}\end{array}$ & High & MDD & High & GP & Yes & 6 wk & MADRS $50 \% \mathrm{M}$ \\
\hline Feighner et $\mathrm{al}^{24}$ & High & Heterogeneous & High & Psychiatrist & No & 4 wk & HAMD $50 \% \mathrm{H}$ \\
\hline Hollyman et $a^{23}$ & High & Heterogeneous & High & Psychiatrist & No & 6 wk & HAMD 50\%H \\
\hline Lecrubier et al ${ }^{25}$ & Low & Heterogeneous & High & Psychiatrist & Yes & 12 wk & HAMD 50\%H \\
\hline Malt et al ${ }^{17 \neq}$ & High & Heterogeneous & High & GP & Yes & 24 wk & MADRS 50\%M \\
\hline $\begin{array}{l}\text { Mynors-Wallis } \\
\text { et } \mathrm{al}^{21}\end{array}$ & High & Heterogeneous & High & GP & No & 12 wk & MADRS \\
\hline Philipp et al ${ }^{20}$ & Low & ModDD & Low & GP & Yes & $8 w k$ & HAMD \\
\hline $\begin{array}{l}\text { Thompson \& } \\
\text { Thompson }{ }^{28}\end{array}$ & Low & Heterogeneous & Low & GP & No & 4 wk & HAMD \\
\hline Thomson et $\mathrm{al}^{22}$ & Low & Heterogeneous & High & GP & Yes & 12 wk & HAMD \\
\hline $\begin{array}{c}\text { Barge-Schaapveld } \\
\text { \& Nicholson }{ }^{29}\end{array}$ & Low & MDD & High & Unclear & Yes & 6 wk & HAMD \\
\hline \multicolumn{8}{|l|}{ SSRI vs placebo } \\
\hline $\begin{array}{l}\text { Doogan } \mathcal{E} \\
\text { Langdon }{ }^{19 *}\end{array}$ & High & MDD & $100 \mathrm{mg}$ sertraline & GP & Yes & 6 wk & MADRS 50\%M \\
\hline Lepola et al ${ }^{18}$ & Low & MDD & 10 mg escitalopram & Unclear & Yes & 8 wk & MADRS 50\%M \\
\hline Malt et al ${ }^{17 \dagger}$ & High & Heterogeneous & 100 mg sertraline & GP & Yes & 24 wk & MADRS \\
\hline $\begin{array}{l}\text { Montgomery } \\
\text { et al }{ }^{30}\end{array}$ & High & MDD & $\begin{array}{c}10 \mathrm{mg} \text { escitalopram } \\
\text { or } 20 \mathrm{mg} \\
\text { citalopram }\end{array}$ & Unclear & Yes & 4 wk & MADRS \\
\hline Wade et al ${ }^{16}$ & High & MDD & 10 mg escitalopram & Unclear & Yes & $8 w k$ & MADRS \\
\hline \multicolumn{8}{|c|}{$\begin{array}{l}\text { HAMD = Hamilton depression scale; } 50 \% \mathrm{H}=\text { discrete outcomes where improvement is a greater than } 50 \% \text { reduction in HAMD; MADRS = Montgomery-Asberg Depres- } \\
\text { sion Rating Scale; } 50 \% \mathrm{M}=\text { discrete outcomes where improvement is a greater than } 50 \% \text { reduction in the MADRS; heterogeneous = patients thought by their general } \\
\text { practitioner to be depressed, which may or may not include patients with major depression as opposed to the studies with only patients with major depression; MDD = } \\
\text { major depressive disorder; ModDD = moderate depressive disorder. }\end{array}$} \\
\hline \multicolumn{8}{|c|}{ * Quality high if adequate sample size, concealment, description of treatment, representative sample, specified inclusion, details of withdrawals, valid outcomes. } \\
\hline \multicolumn{8}{|c|}{ † High dose defined as majority of TCA treated patients receiving at least equivalent of $100 \mathrm{mg} / \mathrm{d}$ amitriptyline (60 mg mianserin). } \\
\hline \multicolumn{8}{|c|}{ f Study has 3 arms (SSRI vs TCA vs placebo). } \\
\hline
\end{tabular}

Only 4 studies used an intention-to-treat analysis, and these studies were the most recent. When studies of low methodological quality for the TCAs $(n=6)$ were removed from analysis, the pooled standardized mean difference or depression score for TCA vs placebo was $-0.50(95 \% \mathrm{CI},-0.65$ to -0.35$)$. For improvement for the TCAs the relative risk was 1.34 (95\% CI, 1.16 to 1.55$)$.

When studies in which at least one half of its assessors were family practitioners were pooled, the standardized mean difference was $-0.43(95 \% \mathrm{CI},-0.58$ to $-0.28)$ and the relative risk was $1.2(95 \% \mathrm{CI}, 1.03$ to 1.4). There were sufficient data to assess continuous outcomes for TCAs at 1 week, 2 weeks, and 4 weeks. The standardized mean difference at 1 week was -0.02 (95\% CI, -0.17 to 0.13$)$, at 2 weeks it was -0.2 (95\% CI, -0.36 to -0.04$)$, and at 4 weeks it was $-0.34(95 \% \mathrm{CI},-0.5$ to -0.18). For studies that used a HAMD $<8$ as an outcome (considered to be a remission) the weighted mean difference was $-3.68(95 \% \mathrm{CI},-5.89$ to -1.47$)$. For the 3 studies that reported no conflict of interest, the weighted mean difference was -4.59 (95\% CI, -6.82 to 2.36 ).

Ten studies included an arm with $100 \mathrm{mg}$ or more of a tricyclic antidepressant or more than $60 \mathrm{mg}$ of mianserin. For the 10 studies in which a high dose was given, the standardized mean difference was -0.42 (95\% CI, -0.56 to -0.29 ). The relative risk for these studies was 1.32 (95\% CI, 1.15 to 1.5 ). For the 4 studies of tricyclic antidepressants using a dose of $100 \mathrm{mg} / \mathrm{d}$ or less, the weighted mean difference (all used the HAMD) was $-3.15(95 \% \mathrm{CI},-5.05$ to -1.24$)$. For the 2 studies of tricyclic antidepressants using a dose of 75 $\mathrm{mg} / \mathrm{d}$, the weighted mean difference was -3.93 (95\% CI, -7.65 to -0.21 ).

Most studies had heterogeneous diagnoses in their participants. Only 2 TCA studies had major depressive disorder as the single diagnosis, and the weighted mean difference for that study was -1.37 (95\% CI, -2.52 to -0.22). ${ }^{19,29}$ For the SSRI studies there were 4 studies 
Figure 2. Tricyclic vs placebo for improvement.

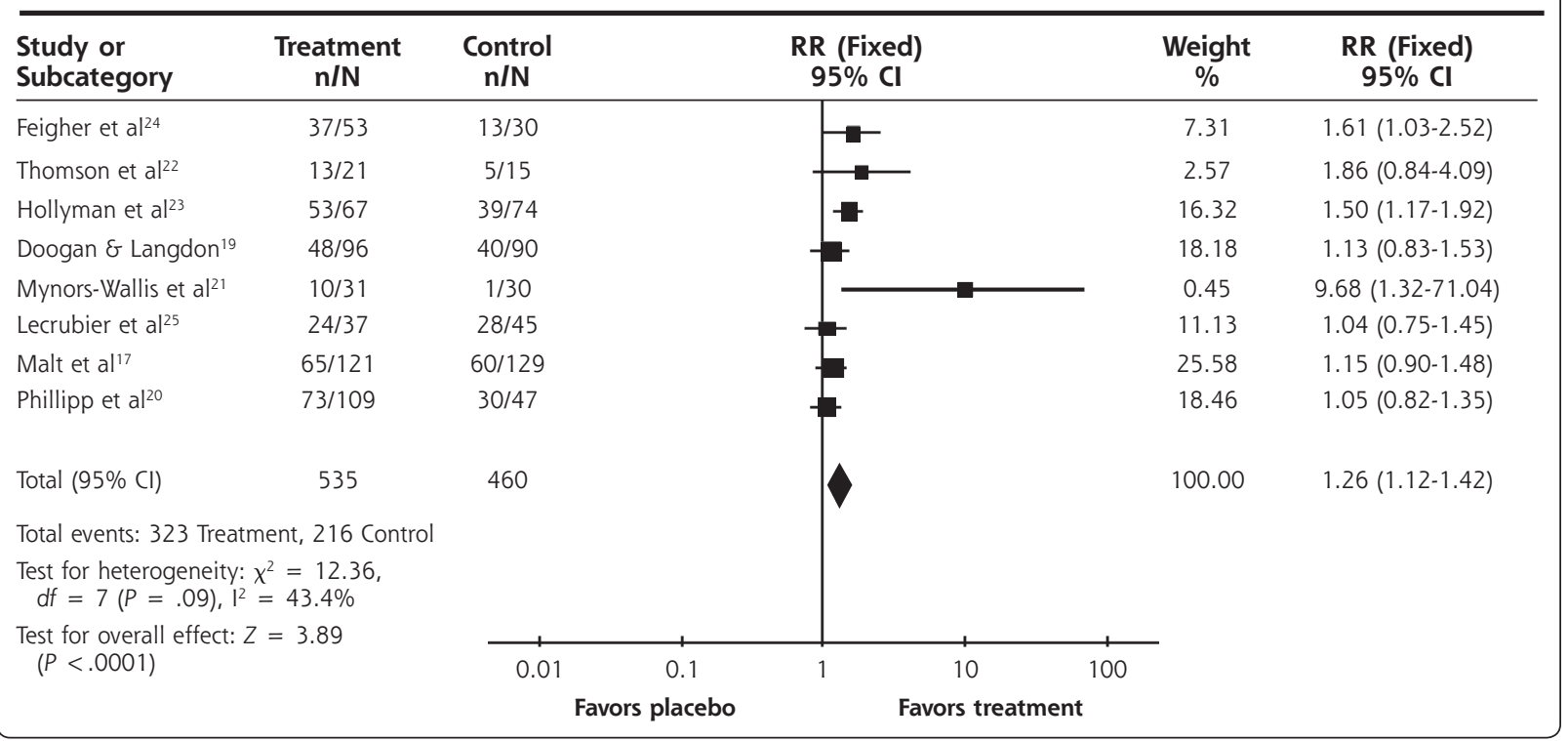

Figure 3. SSRI vs placebo for improvement.

\begin{tabular}{|c|c|c|c|c|c|c|c|}
\hline \multirow{2}{*}{$\begin{array}{l}\text { Study or } \\
\text { Subcategory } \\
\text { Wade et al }{ }^{16}\end{array}$} & \multirow{2}{*}{$\begin{array}{c}\begin{array}{c}\text { Treatment } \\
\text { n/N }\end{array} \\
90 / 191\end{array}$} & \multirow{2}{*}{$\begin{array}{c}\begin{array}{c}\text { Control } \\
\text { n/N }\end{array} \\
64 / 189\end{array}$} & \multicolumn{2}{|r|}{$\begin{array}{l}\text { RR (Fixed) } \\
95 \% \mathrm{Cl}\end{array}$} & & \multirow{2}{*}{$\begin{array}{c}\text { Weight } \\
\% \\
28.16\end{array}$} & \multirow{2}{*}{$\begin{array}{c}\text { RR (Fixed) } \\
\mathbf{9 5 \% ~ C l} \\
1.39(1.08,1.79)\end{array}$} \\
\hline & & & & - & & & \\
\hline Doogan $E$ Langdon ${ }^{19}$ & $50 / 83$ & $40 / 90$ & & - & & 16.80 & $1.36(1.01-1.81)$ \\
\hline Malt et al ${ }^{17}$ & $74 / 122$ & $60 / 129$ & & - & & 25.53 & $1.30(1.03-1.65)$ \\
\hline Lepola et al ${ }^{18}$ & $96 / 156$ & $67 / 154$ & & - & & 29.51 & $1.41(1.14-1.76)$ \\
\hline Total $(95 \%$ Cl) & 552 & 562 & & & & 100.00 & $1.37(1.21-1.55)$ \\
\hline \multirow{2}{*}{\multicolumn{8}{|c|}{$\begin{array}{l}\text { Total events: } 310 \text { Treatment, } 231 \text { Control } \\
\text { Test for heterogeneity: } x^{2}=0.27 \\
\quad d f=3(P=.97), I^{2}=0 \%\end{array}$}} \\
\hline & & & & & & & \\
\hline \multirow{2}{*}{\multicolumn{2}{|c|}{$\begin{array}{l}\text { Test for overall effect: } Z=5.03 \\
\quad(P<.00001)\end{array}$}} & 0.1 & 0.5 & 1 & 10 & & \\
\hline & & \multicolumn{2}{|c|}{ Favors control } & & reatment & & \\
\hline
\end{tabular}

in which all participants had major depressive disorder. ${ }^{16,18,19,30}$ Only 3 of the 4 studies had data suitable for pooling, and the relative risk was 1.39 (95\% CI, 1.21 to 1.61).

\section{DISCUSSION}

We believe our systematic review is the first to compare the efficacy of antidepressants with placebo in the primary care setting. Our results confirm that both TCAs and SSRIs are significantly more effective than placebo for discrete and continuous outcomes. The results seem to apply to major depressive disorder and heterogeneous depression (commonly seen in primary care) and suggest that treating depression with antidepressants is an appropriate activity in primary care. We can only speculate as to the composition of the heterogeneous group, as they had a wide range of definitions but did consider patients with levels of depression less than major depression. Only 1 study analyzed major and minor depression and found no effect for minor depression. ${ }^{23}$

We found only 15 studies based in primary care that met inclusion criteria and provided evidence for the comparative efficacy of TCAs and SSRIs vs placebo. We similarly found relatively few studies in a previous review of trials comparing SSRIs with TCAs in primary care, ${ }^{13}$ as opposed to the considerably larger number of studies conducted with patients from all settings. Williams et $\mathrm{al}^{31}$ found 206 studies comparing a newer with an older antidepressant (123 of which involved an SSRI). They found a benefit for the newer antidepressants ( $R R=1.6,95 \% \mathrm{CI}, 1.3$ to 2.3$)$. Steffens et al, in a US-only based review, found 36 trials comparing a tricyclic with an SSRI. ${ }^{32}$ Most studies included in our 
Figure 4. Tricyclic vs placebo for adverse effects leading to withdrawal.

\begin{tabular}{|c|c|c|c|c|c|c|c|c|}
\hline \multirow{2}{*}{$\begin{array}{l}\text { Study or } \\
\text { Subcategory } \\
\text { Brink et } \mathrm{al}^{27}\end{array}$} & \multirow{2}{*}{$\begin{array}{c}\begin{array}{c}\text { Treatment } \\
\text { n/N }\end{array} \\
3 / 27\end{array}$} & \multirow{2}{*}{$\begin{array}{c}\begin{array}{c}\text { Control } \\
\mathbf{n} / \mathbf{N}\end{array} \\
1 / 25\end{array}$} & \multicolumn{3}{|c|}{$\begin{array}{l}\text { RR (Fixed) } \\
95 \% \mathrm{Cl}\end{array}$} & & \multirow{2}{*}{$\begin{array}{c}\begin{array}{c}\text { Weight } \\
\%\end{array} \\
3.16\end{array}$} & \multirow{2}{*}{$\begin{array}{c}\text { RR (Fixed) } \\
95 \% \text { Cl }\end{array}$} \\
\hline & & & & & $\longrightarrow$ & & & \\
\hline Blashki et al $150 \mathrm{mg}^{26}$ & $3 / 16$ & $2 / 9$ & & & & & 7.78 & $0.84(0.17-4.16)$ \\
\hline Blashki et al 75 mg $^{26}$ & $4 / 13$ & $3 / 9$ & & & & & 10.78 & $0.92(0.27-3.17)$ \\
\hline Feighner et al ${ }^{24}$ & $12 / 93$ & $3 / 50$ & & & & & 11.86 & $2.15(0.64-7.27)$ \\
\hline Thomson et al ${ }^{22}$ & $7 / 31$ & $0 / 28$ & & & & & 1.59 & $13.59(0.81-227.66)$ \\
\hline Hollyman et $\mathrm{al}^{23}$ & $18 / 67$ & $5 / 74$ & & & & & 14.44 & $3.98(1.56-10.12)$ \\
\hline Doogan $E$ Langdon ${ }^{19}$ & $2 / 108$ & $3 / 101$ & & & & & 9.42 & $0.62(0.11-3.65)$ \\
\hline Mynors-Wallis et $\mathrm{al}^{21}$ & $3 / 31$ & $2 / 30$ & & & $\rightarrow$ & & 6.18 & $1.45(0.26-8.09)$ \\
\hline Lecrubier et al ${ }^{25}$ & $10 / 75$ & $4 / 76$ & & & & & 12.08 & $2.53(0.83-7.72)$ \\
\hline Malt et al ${ }^{17}$ & $18 / 121$ & $7 / 129$ & & & $\rightarrow$ & & 20.69 & $2.74(1.19-6.33)$ \\
\hline Philipp et al20 & $1 / 110$ & $0 / 47$ & & & . & & 2.12 & $1.30(0.06-31.28)$ \\
\hline Total $(95 \% \mathrm{Cl})$ & 692 & 578 & & & & & 100.00 & $2.35(1.69-3.46)$ \\
\hline \multicolumn{9}{|c|}{ Total events: 81 Treatment, 30 Control } \\
\hline \multicolumn{9}{|c|}{$\begin{array}{l}\text { Test for heterogeneity: } x^{2}=9.29 \\
d f=10(P=.51), I^{2}=0 \%\end{array}$} \\
\hline \multirow{3}{*}{\multicolumn{2}{|c|}{$\begin{array}{l}\text { Test for overall effect: } Z=4.30 \\
(P<.001)\end{array}$}} & & & & & & & \\
\hline & & 0.001 & 0.01 & 0.1 & 10 & 100 & 1000 & \\
\hline & & \multicolumn{3}{|c|}{ Favors treatment } & \multicolumn{3}{|c|}{ Favors control } & \\
\hline
\end{tabular}

Figure 5. SSRI vs placebo for adverse effects leading to withdrawal.

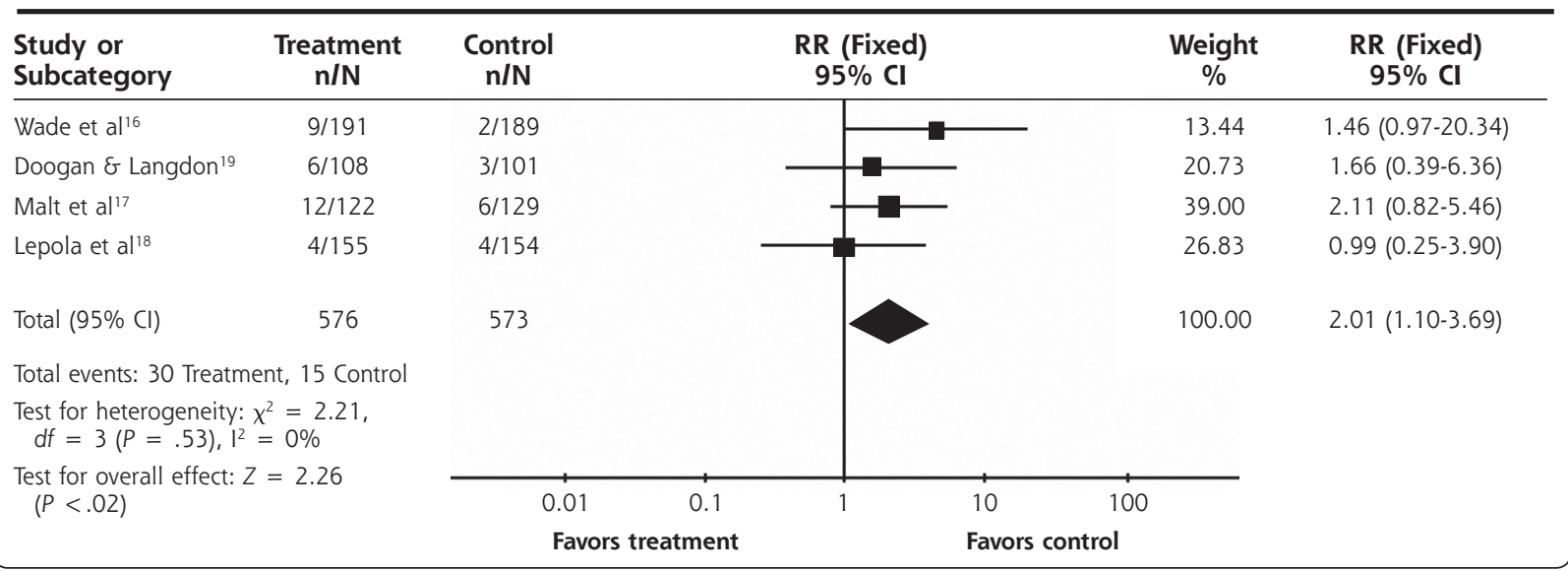

current review were small, phase 3 studies supported by commercial funding (Table 1 ). In fact, all the SSRI vs placebo studies had some commercial involvement. Many studies reviewed were of low methodological quality, and nearly all studies were of short duration, typically 6 to 8 weeks. Our findings are in keeping with a review of 108 studies of newer antidepressants that found both TCAs and SSRIs to be effective in treating depression. ${ }^{33}$ Previous reviews have tended to show that SSRIs are generally more tolerable than TCAs, but evidence is conflicting. Meta-analyses using dropout rates as an index of tolerability have varied findings. While one review ${ }^{34}$ found no difference in dropout rates between SSRIs (32.3\%) and TCAs (33.2\%), another ${ }^{35}$ found a small but statistically significant lower dropout rate for SSRIs (30.8\%) relative to TCAs (33.4\%). In our review focusing only on primary care samples, we found dropout rates for SSRIs of $5.4 \%$ and TCAs of $12 \%$. The numbers needed to harm for the withdrawals from the statistically significant TCA studies ranged from 5 to 11 . In another review of antidepressants in primary care, the relative risk of withdrawal of patients resulting from side effects from SSRIs compared with TCAs was 0.6 (95\% CI, 0.6 to 0.88 ). ${ }^{13}$ The National Institute of Clinical Evidence (UK NICE ) review group of antidepressants considered a weighted or a standardized mean difference of 3 or more to be clinically significant (D Goldberg, personal communication, April 30, 2004). 
We have reported significant numbers needed to treat, which are another way of assessing clinical significance. Primary care clinicians may be more likely than hospital colleagues to alter therapy when side-effects are experienced, even during clinical trials. ${ }^{36}$

Most systematic reviews concerning efficacy of antidepressant medications fail to report a detailed examination of methodological quality and therefore fail to include such criteria when examining treatment effects. Bias in primary studies that is due to poor methodological quality (eg, selection bias, ascertainment bias, inappropriate handling of withdrawals, protocol violations) can lead to exaggeration of treatment effects. A study of trial quality in systematic reviews showed that if low-quality studies were included in pooled estimates of treatment effect, there was a $30 \%$ to $50 \%$ exaggeration of treatment effectiveness. ${ }^{37}$ We did not, however, find any appreciable differences between effects for the high-quality studies compared with the lower quality studies. Another form of bias with meta-analysis is that of publication bias. Our funnel plot suggests that small studies with small effect sizes may be missing. This finding is consistent with a review of all applications to the US Food and Drug Administration, which, on examination of all submitted trials of newer antidepressant medications, found that the benefit of antidepressant medications was much smaller when all studies were considered than when only the published studies were considered. ${ }^{38}$ The use of standardized mean difference was necessary, as the studies with continuous outcomes used a number of different scales-HAMD in the older studies and MADRS in more recent years. It would be helpful for future meta-analyses for both the HAMD and MADRS to be used to facilitate pooling.

Our finding of a significant benefit when pooling the results of 2 studies is consistent with a recent metaanalysis of studies in all settings, which found a benefit from treatment with low-dose tricyclic antidepressants. ${ }^{39}$ Neither of the findings from the 2 studies in our review were statistically significant, which suggests that larger trials are needed in the primary care setting to clarify such issues as dose of antidepressant medication. ${ }^{26,28}$ The review of studies of low-dose medications found that no evidence of increased benefit, but there was an increase in side effects with higher dosages. Our results were similar to those of that review, but we did not find a significant increase in adverse effects.

Most of the trials reviewed here studied patients with a range of depression severity. Only 2 TCA studies included patients with major depressive disorder. ${ }^{19,29}$ Three studies of SSRIs included only patients with major depressive disorder. ${ }^{16,18,19}$ As patients in primary care settings have a range of depression severity, the generalizability of the results of these studies to primary care is reasonable. ${ }^{40}$ Advice on using TCAs has stressed that patients will not obtain a benefit from medication until 2 weeks of treatment has passed. Our findings are in agreement. Also at issue is that primary care populations may benefit from antidepressant medication only when it is given by a psychiatrist. Our significant findings for continuous and discrete outcomes contradict this concern.

We found evidence that both TCAs and SSRIs are more effective than placebo. This finding needs to be tempered with the knowledge that some publication bias may have occurred and that many studies in the review were small and of variable quality. Gaps in the literature include a lack of attention to the treatment of specific diagnostic groups, in particular patients with minor depression. Further research is needed on these groups of patients in addition to longer and larger trials of low-dose TCAs. In terms of practice, many guidelines are recommending SSRIs rather than TCAs because of safety. Both are effective, and if safety is not an issue, then individual tolerability to side effects will determine types of medications used.

To read or post commentaries in response to this article, see it online at http://www.annfammed.org/cgi/content/full/3/5/449.

Key words: Antidepressant agents, tricyclic; antidepressive agents, second-generation; placebo; primary health care

An earlier form of this review was presented at the Annual Scientific Meeting of the North Atlantic Primary Care Research Group, October 2003. It was awarded an extended paper award.

Funding support: Funding Body Chief Scientist Office, Scotland.

\section{References}

1. Arya R. The management of depression in primary health care. Curr Opin. 1999;12:103-107.

2. Suh T, Gallo JJ. The management of depression among general medical service providers. Psychol Med. 1999;27:1051-1063.

3. Jenkins GC. Management of patients with depression. Br J Gen Pract. 2001;51:932-933.

4. King M, Davidson O, Taylor F, Haines A, Sharp D, Turner R. Effectiveness of teaching general practitioners skills in brief cognitive behaviour therapy to treat patients with depression: randomised controlled trial. [comment]. BMJ. 2002;324:947-950.

5. Joffe R, Sokolov S. Antidepressant treatment of depression : a metaanalysis. Can J Psychiatr. 1996;41:613-616.

6. American Psychiatric Association. Practice guidelines for major depressive disorder in adults. Am J Psychiatr. 1993;150:suppl 4.

7. Goldberg D, Privett M, Ustun B, Simon G, Linden M. The effects of detection and treatment on the outcome of major depression in primary care: a naturalistic study in 15 cities. Br J Gen Pract. 1998;48:1840-1844.

8. Gill D. Prescribing antidepressants in general practice. Systematic review of all pertinent trials is required to establish guidelines. BMJ. 1997;314:826-827.

9. National Coordinating Centre for Health Technology Assessment. Health technology briefing paper: drug treatment of mild depression. 5018 2000. Available at: http://www.ncchta.org. 
10. Cochrane Collaboration Depression Anxiety and Neurosis Review Group. Available at: http://www.cochrane.org.

11. Ellis PM, Smith DA. Treating depression: the beyond blue guidelines for treating depression in primary care. Med J Aust. 2002;176:S77-S83.

12. Mulrow CD, Williams LW, Chiquette E, Aguilar C, Hitchcock-Noel P, Lee $\mathrm{S}$, et al. Efficacy of newer medications for treating depression in primary care patients. Am J Med. 2000;108:54-64.

13. MacGillivray S, Arroll B, Hatcher $S$, et al. Efficacy and tolerability of selective serotonin reuptake inhibitors compared with tricyclic antidepressants in depression treated in primary care: systematic review and meta-analysis. BMJ. 2003;326:1014-.

14. Starfield B. Is primary care essential? Lancet. 1994;344:1129-1133.

15. Mulrow CD, Oxman A. Cochrane collaboration handbook: In: Cochrane Library. Issue 4. Oxford: Update Software; 1997.

16. Wade A, Lemming OM, Hedegaard KB. Escitalopram $10 \mathrm{mg} /$ day is effective and well tolerated in a placebo-controlled study in depression in primary care. Int Clin Psychopharmacol. 2002;17:95-102.

17. Malt UF, Robak OH, Madsbu H-P, Bakke O, Loeb M. The Norwegian naturalistic treatment study of depression in general practice(NORDEP)-1:randomised double blind study. BMJ. 1999;318:1180-1184.

18. Lepola $U$, Loft $H$, Reines EH. Escitalopram is efficacious and well tolerated for the treatment of depression in primary care. Annual meeting the American medical association. New Orleans 2001.

19. Doogan DP, Langdon CJ. A double-blind, placebo controlled comparison of sertraline and dothiepin in the treatment of major depression in general practice. Int Clin Psychopharmacol. 1994;9:95-100.

20. Philipp M, Kohnen R, Hiller KO. Hypercium extract versus imipramine or placebo in patients with moderate depression: randomised multicentre study of treatment for eight weeks. BMJ. 1999;319:1534-1539.

21. Mynors-Wallis LM, Gath DH, Lloyd-Thomas AR, Tomlinson D. Randomised controlled trial comparing problem solving treatment with amitriptyline and placebo for major depression in primary care. BMJ. 1995:310:441-445.

22. Thomson J, Rankin H, Ashcroft GW, Yates CM, McQueen JK, Cummings SW. The treatment of depression in general practice: a comparison of L-tryptophan, amitriptyline and a combination of L-tryptophan and amitriptyline with placebo. Pscyh Med. 1982;12:741-751.

23. Hollyman JA, Freeling P, Paykell ES, Bhat A, Sedgwick P. Doubleblind placebo-controlled trial of amitriptyline among depressed patients in general practice. J R Coll Gen Pract. 1988;38:393-397.

24. Feighner JP, Brauzer B, Gelenberg AJ, et al. A placebo-controlled mulitcenter trial of limbitrol versus its components amitriptyline and chlordiazepoxide. Psychopharmacol. 1979;61:217-225.
25. Lecrubier Y, Bourin M, Moon CA, et al. Efficacy of venlafaxine in depressive illness. Acta Psychiatr Scand. 1997;95:485-493.

26. Blashki TG, Mowbray R, Davies B. Controlled trials of amitriptyline in general practice. BMJ. 1971;1:133-138.

27. Brink CW, vdKrogt JP, Dunbar GC, Behagel LH. A controlled clinical trial of mianserin and placebo in the treatment of depression in general practice. J Drug Ther Res. 1984;9:513-517.

28. Thompson C, Thompson CM. The prescribing of antidepressants in general practice II A placebo controlled trial of low-dose dothiepin. Human Psychopharmacol. 1989;4:191-204.

29. Barge-Schaapveld DQ, Nicholson NA. Effects of antidepressant treatment on the quality of daily life: an experience sampling study. J Clin Psych. 2002;63:477-485.

30. Montgomery SA, Loft H, Sanchez C, Reines EH, Papp M. Escitalopram (s enantiomer of Citalopram):clinical efficacy and onset of action predicted from a rat model. Pharmacol Toxicol. 2001;88:282-286.

31. Williams JW, Mulrow CD, Chiquette E, Noel PH, Acaster C, Cornell J. a systematic review of newer pharmacotherapies for depression in adults: evidence report summary. Ann Intern Med. 2000;132:743-756.

32. Steffens DC, Krishnan KR, Helms MJ. Are SSRIs better than TCAs? Comparison of SSRIS and TCAs: a meta-analysis. Depress Anxiety. 1997:6:10-18.

33. Anderson IM. Meta-analytical studies on new antidepressants. Br Med Bull. 2001;57:161-178.

34. Song F, Freemantle N, Sheldon $T A$, et al. Selective serotonin reuptake inhibitors compared with tricyclic antidepressants: a meta-analysis of efficacy and acceptability. BMJ. 1993;306:683-687.

35. Anderson IM, Tomenson BM. Treatment discontinuation with selective serotonin reuptake inhibitors compared with tricyclic antidepressants: a meta-analysis. BMJ. 1995;310:1433-1438.

36. Simon GE. Venlafaxine is more effective than selective serotoninreuptake inhibitors for depression. Am Coll Phys Journal Club. 2002;137:101.

37. Moher D, Cook DJ, Jadad AR, et al. Assessing the quality of reports of randomised trials: implications for the conduct of meta-analyses. Health Technol Assess. 1999;3:1-98.

38. Kirsch I, Moore TJ, Scoboria A, Nicholls SS. The emperor's new drugs: an analysis of antidepressant medication data submitted to the US Food and drug administration. Prep Treat 2002;5:1522-1534.

39. Furukawa TA, McGuire $H$, Barbui C. Meta-analysis of effects and side effects of low dosage tricyclic antidepressants: systematic review. BMJ 2002;325:991-1000.

40. Arroll B, Goodyear-Smith F, Lloyd T. Depression in patients in an Auckland General Practice. NZ Med J. 2002;115:176-179. 